\title{
Tuberculosis and Behavioural Risk Factors: The Case of North- Western Nigeria
}

\author{
Fada, Abubakar Garba (PhD), \\ Department of Geography, Usmanu Danfodiyo University, Sokoto, Nigeria.
}

\begin{abstract}
Behavioural risk factors affect the spread of diseases, particularly infectious diseases like tuberculosis (TB), the transmission which is associated with several factors, including consumption of unpasteurised milk. The few studies that have been conducted on the role of behavioural risk factors on disease transmission in North-western Nigeria are also inconclusive. This study, therefore, examined the prevalence of pulmonary TB in the region with a focus on these factors, using a survey design and the disease ecology concept as the framework. Random sampling was used to collect data from the records of 15 Directly Observed Therapy Short-course (DOTS) centres along Fulani route of seasonal migration. A structured questionnaire was administered to 461 selected patients, and data collected on behavioural risk factors included 'visits to health centre to treat TB', 'smoking' and 'consumption of unpasteurized milk' as well as perceived causes of the disease. Simple Linear Regression and Analysis of Variance (ANOVA) were used to analyze data at $p<0.05$. Results of the regression showed 'ever visited a health centre to treat TB' with the highest contribution (Beta $=0.853$ ), followed by 'ever been a smoker' $(B e t a=0.953)$ for the behavioural factors; whist heredity (Beta $=0.265)$ and God's wish $(B e t a=0.229)$ were perceived as the main causes of TB. There was no statistical significance of both the behavioural $[\mathrm{F}(15,44)=1.397 ; \mathrm{p}=0.191]$ and perceived $[\mathrm{F}(19,130)=0.525, \mathrm{p}=0.947]$ factors. It was concluded that behavioural factors do not affect the prevalence of TB in North-western Nigeria. Thus, cognizance needs to be taken of other factors in TB monitoring and control within the region.
\end{abstract}

Keywords: Pulmonary tuberculosis prevalence, Disease ecology, Unpasteurized milk, Directly Observed Therapy Short-course (DOTS), North-western Nigeria.

\section{INTRODUCTION}

Within the last two decades, infectious diseases have shown an unprecedented and rather unexpected rise in infectivity despite the strides made in immunization, provision of healthcare facilities and services, discovery of drugs and better understanding of the nature of many of these diseases. Tuberculosis (TB) is one of these infectious diseases that are on the rise. It is caused by the pathogens, Mycobacterium tuberculosis (in humans) and Mycobacterium bovis (in animals), and spread through droplets of sputum or particles of dust, which are inhaled into the lungs. Pulmonary tuberculosis simply refers to tuberculosis of the lungs or infection of the respiratory tract. The disease agent has a remarkable ability to exist in the human host as a latent asymptomatic form for more than four months before manifesting itself as a disease. As an infectious disease, TB has social and behavioural characteristics which lend it for geographic study, particularly with the increased risk from the disease as a result of HIV infection to which it is linked opportunistically, as well as the global emergence of multi-drug-resistant strains of tuberculosis (MDR-TB), which further compounds the problem.

The World Health Organization (WHO, 2006) ranked Nigeria as the world's $5^{\text {th }}$ largest country with tuberculosis cases and puts $75 \%$ of the new TB cases as pulmonary sputum smear-positive (SS+). According to the United States Embassy in Nigeria (2012), there were an estimated 320,000 prevalent cases of TB in 2010 and the age groups commonly affected were the most productive $(25-34)$, accounting for $33.6 \%(15,303)$ of the smear positive cases registered in the year. WHO also estimates that $27 \%$ of Nigeria's TB patients are HIVpositive which gives an insight on the dangers of increasing TB cases in the country since the two diseases are opportunistically-related. This paper is therefore aimed at examining the interrelationships between the prevalence of tuberculosis and behavioural risk factors within the North-western region of Nigeria .

\section{LITERATURE REVIEW AND CONCEPTUAL FRAMEWORK}

There are always interactions between social, economic, political and even cultural factors in effecting disease transmission (Peter et al, 1997). Based on this understanding, the concept of disease ecology was used as a framework to guide this study. The concept stipulates that our understanding of the prevalence or incidence of a disease requires a parallel understanding of the prevailing socio-economic, cultural/behavioural, environmental and biological characteristics of the population group under consideration, in addition to the characteristics of the disease agent itself. The concept is thus concerned with "the ways human behaviour, in its 
cultural and socio-economic context, interacts with environmental conditions to produce or prevent disease (Meade and Earickson, 2000). Culture in this framework and in our own context, has to do with practices, belief systems, norms and values, perceptions and behaviours that include consumption of unpasteurized milk as lifestyle factor. The conceptual framework is therefore based on measuring and understanding behavioural risk factors of the sample population in analyzing tuberculosis prevalence within the region.

The perception of the lay person of the causes of a disease has important implications for his utilization of healthcare services and health-seeking behaviour. This may go contrary to professional biomedical explanations of the cause of a disease. Perceived causes help to explain the meanings of a health problem and its implications based on cultural, familial, and personal background. Misconception about the correct cause of a disease could affect patient's attitude towards health-seeking and preventive behaviour. Such beliefs may cause delays in seeking early care and non-adherence to medication. Gesler (2002: 196) noted this role of cultural differences in creating different health belief practices and experiences.

Delay in seeking healthcare in tuberculosis detection and treatment is sometimes affected by the person's perception of the disease as well as poor or lack of knowledge of the disease. A study by Oluwadare and Bosede (2010) on the pattern of health-seeking behaviour on tuberculosis patients in Ekiti State, Nigeria for example, showed that $52 \%$ and $43 \%$ of male and female respondents respectively believe that TB is "slightly dangerous", thus indicating appreciable level of knowledge of the infection. Smoking habit and poverty were the most acknowledged causes of TB while poverty and drinking of alcohol were also mentioned. There were also other superstitious beliefs for the cause of TB, such as spiritual attack from enemies, ancestral curse and result of violation of cultural mores and morale of the society. Obuku et al (2012) also carried out a study on the socio-economic determinants and prevalence of tuberculosis knowledge in Uganda with the aim of assessing knowledge of the disease and identifying the associated socio-demographic determinants in three urban centres using survey questionnaire on persons aged 18 years and above. The level of TB knowledge, stratified as knowledge of cause, symptoms, transmission, risk groups, prevention, and treatment was found to be correlated with age, sex, marital status, educational level, employment and distance from health unit..

Lifestyle factors, such as smoking which could be a stress-coping behaviour, may be a determinant of health outcome. This has been demonstrated by Peter et al (1997) who examined the health status and risk factors of semi-nomadic pastoralists in Mongolia using a geographical approach. Their study found significant associations between certain health status indicators and lifestyle factors. As such, cigarette smoking may reflect poorer health related habits and socio-cultural behaviour that may independently increase risk of infection as has been observed to increase the chances of developing clinical TB four-fold (Lam et al, 2004; Arcavia, 2004, Ariyothai et al, 2004; Singh et al, 2005; Lien et al, 2009; Chigbu et al 2010 and Ekrakene and Igelele 2010). Ekrakene and Igeleke (2010)'s study on 50 active smoking men and 50 passive smoking men randomly selected from the incoming patients in Central Hospital, Benin City, Nigeria in particular, indicated positive tests of Mycobacterium tuberculosis for both passive and active smokers alike, with active smokers having higher casualties.

\section{THE STUDY AREA}

The study area consists of a section of Udo's (1970) Rima and Middle Niger Valley regions of Nigeria (Figure 1) covering sections within the present Sokoto, Kebbi and Niger States. The Rima region consists of the Sokoto basin (about 57936.50 square kilometres) and that of the Rima basin (about 56327.20 square kilometres) while the Middle Niger valley region starts from Kebbi State in Yauri Emirate down to Ilorin in Kwara State. However, our study area stops at Kainji in Niger State. It lies between Longitudes $8^{\circ} 00^{\prime}$ and $14^{\circ} 00^{\prime}$ East and Latitudes $3^{\circ} 30^{\prime}$ and $7^{\circ} 30^{\prime}$ North.

There are a number of ethnic groups within the region, but the Hausa-Fulani dominate. In the far north, there are the Hausa-Fulani and Zabarmawa. As one moves southwards, the Kambari, Dakarkari, Gwagi and Nupe dominate. There are thus people of varied cultures living in the region. The primary activity of the people is farming with variations depending on the location. Cattle are mostly kept by the Fulani, together with few ruminants that cater for immediate or emergency needs during festivities and to provide for medication. However, the Hausas have nowadays learnt to keep some cattle in their houses for their daily needs of dairy byproducts, particularly yoghurt (nono) and butter in the absence of the Fulani as well as for the purpose of fattening of the animal prior to sale. In fact, yoghurt is consumed with millet balls (fura) in every household in the northern most part of the study area, i.e. Sokoto, Kebbi and Zamfara. 


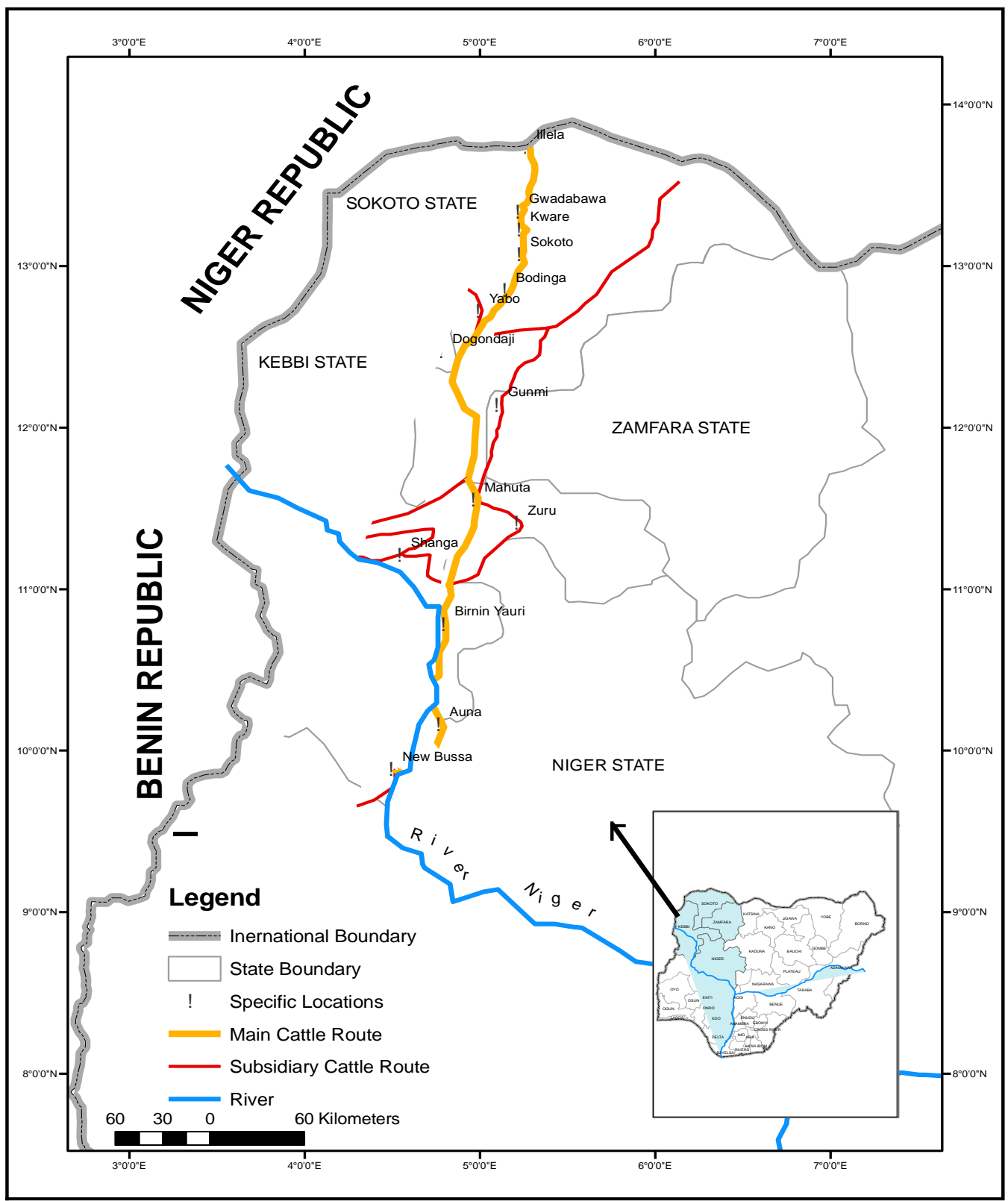

Source: Fieldwork, 2010

Figure 1: Fulani Transhumance Routes in the Study Area

\section{RESEARCH METHODS}

Primary data on behavioural risk factors of the prevalence and spread of TB in fifteen (15) DOTS centres along Fulani route of seasonal migration were captured using a structured questionnaire. The risk factors included habits such as smoking and alcoholism; history of taking fresh milk or its products; knowledge about the disease; and access to healthcare facilities and services. 'History of taking milk or its products' refers to the length of period (in completed months) the respondent had taken or has been taking unpasteurized milk or its products, and whether he/she had noticed any change in his/her health status during the period. 'Habits' were reported in terms of whether the respondent had been involved in a particular risk habit and for how long, and if so whether that has had any effect on his/her health. 'Contacts with animals and other populations' refer to how often the respondent sleeps in the midst of animals (as he takes care of them) so as to determine the degree of contact. For the purpose of clarity, 'prevalence' refer to the number of TB cases reported in the sampled areas in relation to time and space, that is, the total number of existing cases over a specific time frame (within the year 2010) in different places.

The sampling frame was the case register of all TB patients diagnosed with the disease (treated, currently receiving treatment, abscondments, or diseased) from which the sample was drawn. This was based on the premise that treatment of tuberculosis lasts for complete eight (8) months and whosoever is administered the questionnaire is deemed to be part of the population of patients registered within the eight-month period. In 
administering the questionnaire, a purposive but simple random sampling technique was employed. It is purposive for the fact that the research is targeted on TB patients. In determining the sample size, Araoye's (2004) formula was used, i.e.

$$
n f=\frac{n}{\frac{1+(n)}{(N)}}
$$

Where $n f=$ the desired sample size when population is less than 10,000

$n=$ desired sample size when population is more than 10,000

$N=$ estimate of the population

With a cumulative number of patients in the selected DOTS centres as 1736 for 2010 ,

$$
n f=\frac{\frac{400}{1+400}}{1736} \quad=461
$$

Therefore, our estimated sample for all the DOTS centres was 461.The sample was proportionately taken from the different DOTS centres in accordance with the tuberculosis prevalence recorded by each during the year. As patients presented themselves for treatment and advice, questionnaires were administered to them using vernacular by the DOTS Officers.

The Regression Analysis and Analysis of Variance (ANOVA) were used to examine and test the relationships between TB prevalence and behavioural risk factors respectively. In the regression model, tuberculosis prevalence $\left(\mathrm{Y}_{i}\right)$ was the response (target) variable, while behavioural risk factors were the explanatory (predictor) variables such as 'sleeping in the midst of animals', 'consumption of unpasteurized milk', 'ever smoked cigarette' dissatisfaction with the state of health', 'ever visited a health centre' 'access to healthcare services' and 'perception of the causes of TB'. A regression coefficient (odds ratio) of 1.0 meant that the predictor in question had no effect on the response variable.

\section{RESULTS AND DISCUSSION}

Table 1 shows that 'ever visited a health centre to treat TB' and 'consumption of unpasteurized milk and its products' pose similar risk (34.95\%), which is the highest among the factors. These are followed by 'ever smoked cigarettes' $(27.88 \%)$ and the least risk is with 'sleeping in the midst of animals' $(2.21 \%)$. All these are variables known to cause or enhance tuberculosis infection (Lam et al, 2004; Arcavia, 2004; Ariyothai et al, 2004; Beals, 2007; Lin et al, 2009 and Chigbu et al 2010). This supports the view that availability of unpasteurized milk and its products influences the prevalence of TB in the region. 'Sleeping in the midst of animals' does not, however, seem to play a significant role in the prevalence of tuberculosis and thus had the least response, while 'ever been infected' and 'consumption of unpasteurized milk and its products' had the highest response. On the contrary, least responses for 'sleeping in the midst of animals' is indicative of few cases of zoonotic infection of tuberculosis between humans and animals as a result of living in the same environment or through perspiration. This finding does not agree with Ayele et al's (2004) and Shitaye et al's (2007) findings that close contacts with infected animals could represent one of the main causes of tuberculosis infection for humans. Could it be that the authors were referring to sleeping in the midst of TB-infected animals? It is obvious that where the animals are healthy, contact does not lead to infection.

Table 1: Behavioral Rusk Factors

\begin{tabular}{lcccc}
\hline Health facility & $\begin{array}{l}\text { Ever visited health } \\
\text { centre to treat TB }\end{array}$ & $\begin{array}{l}\text { Ever smoked } \\
\text { cigarettes }\end{array}$ & $\begin{array}{l}\text { Sleeping in midst } \\
\text { of animals }\end{array}$ & $\begin{array}{c}\text { Consumption } \\
\text { of fresh milk }\end{array}$ \\
\hline GH Illela & 17 & 12 & 0 & 18 \\
PHC Gwadabawa & 3 & 9 & 0 & 9 \\
CHC Kware & 2 & 8 & 0 & 0 \\
S/H.Sokoto & 20 & 8 & 0 & 2 \\
GH Bodinga & 0 & 4 & 0 & 5 \\
GH Yabo & 0 & 0 & 0 & 1 \\
GH Dogondaji & 3 & 2 & 0 & 6 \\
GH Gummi & 10 & 2 & 0 & 1 \\
GH Zuru & 15 & 0 & 0 & 2 \\
PHC Mahuta & 2 & 2 & 0 & 5 \\
GH Shanga & 2 & 1 & 0 & 7 \\
GH Yauri & 0 & 1 & 0 & 3 \\
GH Warra & 1 & 7 & 3 & 1 \\
RHC Auna & 7 & 1 & 1 & 1 \\
GH New Bussa & 7 & $\mathbf{6 3}(\mathbf{2 7 . 8 8 \% )}$ & $\mathbf{5}(\mathbf{2 . 2 1 \%})$ & $\mathbf{7 9}(\mathbf{3 4 . 9 5 \% )}$ \\
Total & $\mathbf{7 9}(\mathbf{3 4 . 9 5 \% )}$ & & & \\
\hline
\end{tabular}


Source: Fieldwork, 2010

Table 1 also shows variations among the DOTS centres. Those with the highest prevalence (Illela, Sokoto and Zuru) have the highest risk of infection with 'consumption of unpasteurized milk' and 'ever visiting a health centre to treat TB', perhaps by virtue of their population size. This may suggest some sort of synergy among the factors as their respective roles were not well-pronounced in some stations.

Results of the Regression Analysis carried out (Table 2) again showed that 'ever visited a health centre to treat $\mathrm{TB}$ ' has the highest contribution (Beta $=0.583$ ) in the prevalence of tuberculosis among the behavioural risk factors, followed by 'ever been a cigarette smoker' (Beta $=0.395)$ and then having 'sleeping in the midst of animals' (Beta $=0.212$ ), similar to what the raw data shows. Consumption of unpasteurized milk seems to have a negative contribution (Beta=-1.945). The results disagree with the assertions of many scholars (Erahl et al, 2009; Chigbu et al, 2010; Lopez De Fede et al, 2008; Muniyandi et al, 2008; and Mackenbach et al, 2008) in some respects. It particularly disagrees with the works of Daborn et al (1996) who found that TB infection could be due to bacteria-containing aerosols shed by infected animals, and the works of Alhaji et al (1977), Ayele et al (2004), Thoen et al (2006), Shitaye et al (2007), Yumi et al (2007), Ofukwu et al (2008), Beals (2007) and Abubakar et al (2011) who suggest the possibility of contracting a zoonotic infection between humans and animals due to staying with the animals. On the contrary, it agrees with Lienhardt et al (2003) who found the risk of being infected being high among individuals with former history of tuberculosis. On the issue of smoking, the finding agrees with Ekrakene and Igeleke (2010) who found association between TB and smoking, as well as Oluwadare and Bosede (2010) who found smoking habit as one of the most acknowledged causes of $\mathrm{TB}$, together with other superstitious beliefs such as spiritual attack from enemies, ancestral curse and result of breaking of cultural taboos.

Table 2: Results of regression analysis for behavioural factors

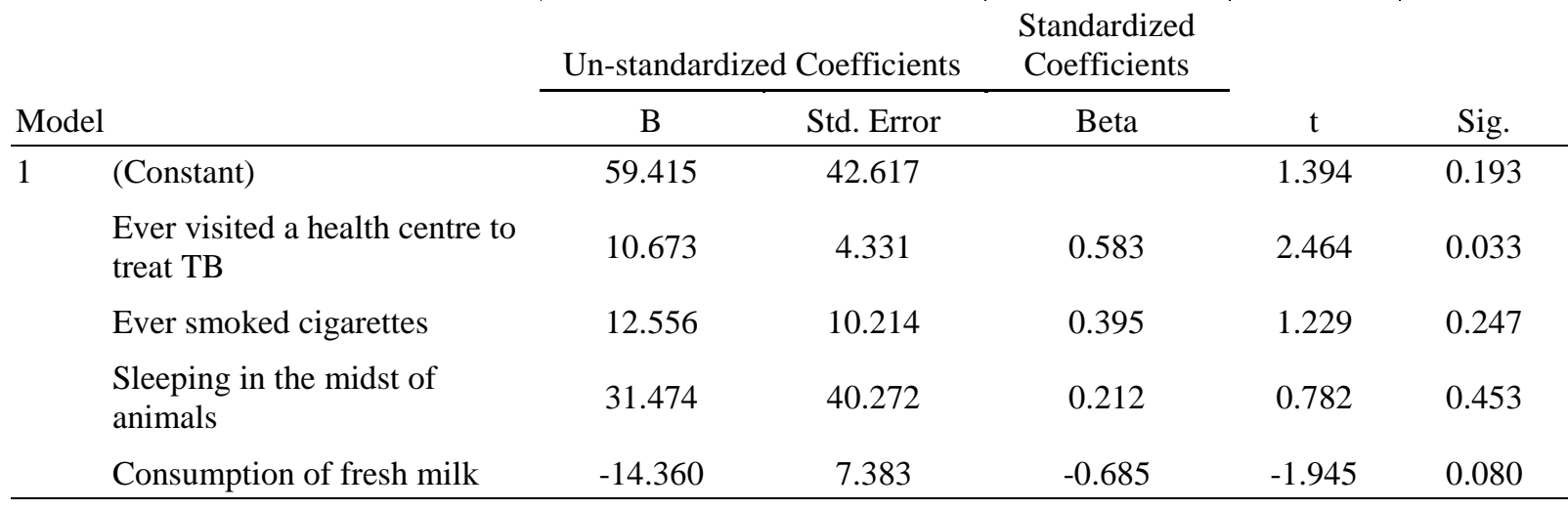

a. Dependent Variable: Prevalence

The Analysis of Variance carried out to test the significance of the behavioural factors in affecting the prevalence of tuberculosis in the study area (Table 3) also indicated no statistically significant difference in the means of the variables considered, $\mathrm{F}(15,44)=1.397 ; \mathrm{p}=0.191$, at 0.05 significance level.

Table 3: Results of analysis of variance for behavioural factors

\begin{tabular}{lccccc}
\hline & Sum of Squares & df & Mean Square & F & Sig. \\
\hline Between Groups & 24.197 & 15 & 1.613 & 1.397 & 0.191 \\
Within Groups & 50.803 & 44 & 1.155 & & \\
Total & 75.000 & 59 & & & \\
\hline
\end{tabular}

On perception of the causes of tuberculosis, responses are presented in Table 4.

Table 4: Respondents' belief on the causes of tuberculosis 
Tuberculosis and Behavioural Risk Factors: The Case with North-Western Nigeria

\begin{tabular}{|c|c|c|c|c|c|c|c|c|c|c|}
\hline \multirow{2}{*}{$\begin{array}{l}\text { Health } \\
\text { Facility }\end{array}$} & \multicolumn{10}{|c|}{ Causes of Tuberculosis } \\
\hline & Dust & $\begin{array}{c}\text { God } \\
\text { Ordained }\end{array}$ & Spiritual & Heredity & $\begin{array}{c}\text { Cold } \\
\text { weather } / w \\
\text { ater }\end{array}$ & Diet & Infection & $\begin{array}{l}\text { Unpas. } \\
\text { Milk }\end{array}$ & Smoking & $\begin{array}{l}\text { Don't } \\
\text { Know }\end{array}$ \\
\hline Gwadabawa & 0 & 4 & 0 & 0 & 2 & 0 & 4 & 0 & 4 & 12 \\
\hline Kware & 0 & 0 & 4 & 0 & 0 & 0 & 13 & 0 & 2 & 3 \\
\hline Sokoto & 17 & 23 & 3 & 8 & 18 & 2 & 27 & 1 & 27 & 8 \\
\hline Dogondaji & 0 & 0 & 0 & 0 & 1 & 0 & 6 & 0 & 1 & 0 \\
\hline Gummi & 1 & 0 & 0 & 0 & 0 & 0 & 4 & 0 & 0 & 5 \\
\hline Zuru & 11 & 2 & 0 & 0 & 7 & 0 & 30 & 0 & 0 & 1 \\
\hline Mahuta & 3 & 1 & 0 & 0 & 1 & 0 & 4 & 0 & 0 & 2 \\
\hline Shanga & 2 & 0 & 0 & 0 & 1 & 1 & 13 & 2 & 1 & 1 \\
\hline Yauri & 18 & 0 & 0 & 0 & 7 & 0 & 21 & 1 & 17 & 8 \\
\hline
\end{tabular}

Source: Fieldwork, 2010

The table shows that $11.06 \%$ of the respondents do not know the causes of tuberculosis. This lack of knowledge, which might be associated with low literacy levels, particularly when associated with lack of employment, could contribute to delays in seeking healthcare and hence the progression of the disease. Among the perceived causes, $14.09 \%$ of the respondents attributed it to dust, $9.97 \%$ to cold weather or cold water and $12.14 \%$ to smoking. This result is at variance with the ones obtained by Karim et al (2011) and Legesse et al (2010) that $45.9 \%$ of their respondents attributed the cause of tuberculosis to cold air, 38.0\% to the shortage of food, $21.8 \%$ to dust and $16.4 \%$ to smoking. Again the table indicates that $10.41 \%$ of the respondents attribute TB infection to the wish of God, $2.81 \%$ to spiritual attacks, and $2.16 \%$ to heredity, $0.86 \%$ to the nature of the diet, $35.14 \%$ to microbial infection and $1.51 \%$ to consumption of unpasteurized milk. These diverse beliefs could serve as indicators of the ways tuberculosis is understood and treated through different belief systems, in terms of the health seeking behaviour of the patient. The issues of consumption of unpasteurized milk and smoking are discussed here as perceptions of the respondents. Interestingly from the table, a larger number (35.14\%) of the respondents believe in microbial infection as the cause of tuberculosis. The fact that there are other beliefs about the cause of the disease points to the different ways the disease could be treated, in terms of alternative therapies and delays in seeking healthcare, which according to Oluwadare and Bosede (2010) are a function of the level of education, followed by gender and age.

To examine the role of perceived causes of TB on its prevalence, the Multiple Regression Analyses was carried out. The results presented in Table 5 show that the highest positive contribution comes from 'heredity' cause (Beta $=0.265)$, followed by 'God's wish' (Beta=0.229), signifying that they are possible risk factors.

Table 5: Results of regression analysis on perceived causes of TB

\begin{tabular}{|c|c|c|c|c|c|c|}
\hline \multirow[b]{2}{*}{ Model } & & \multicolumn{2}{|c|}{ Unstandardized Coefficients } & \multirow{2}{*}{$\begin{array}{c}\text { Standardized } \\
\text { Coefficients } \\
\text { Beta } \\
\end{array}$} & \multirow[b]{2}{*}{$\mathrm{t}$} & \multirow[b]{2}{*}{ Sig. } \\
\hline & & $\mathrm{B}$ & Std. Error & & & \\
\hline \multirow[t]{11}{*}{1} & (Constant) & -0.769 & 1.713 & & -0.449 & 0.677 \\
\hline & Dust & 3.679 & 0.365 & 0.110 & 10.079 & 0.001 \\
\hline & God & 3.600 & 0.375 & 0.229 & 9.588 & 0.001 \\
\hline & Spiritual & 4.301 & 1.490 & 0.026 & 2.887 & 0.045 \\
\hline & Heredity & 3.598 & 0.159 & 0.265 & 22.638 & 0.000 \\
\hline & Coldwater & 3.966 & 2.859 & 0.019 & 1.387 & 0.238 \\
\hline & Diet & 3.722 & 0.652 & 0.147 & 5.712 & 0.005 \\
\hline & Infection & 4.273 & 2.435 & 0.074 & 1.755 & 0.154 \\
\hline & Unpastmilk & 3.322 & 0.807 & 0.046 & 4.118 & 0.015 \\
\hline & Smoking & 3.383 & 0.534 & 0.169 & 6.334 & 0.003 \\
\hline & Don know & 3.522 & 0.465 & 0.177 & 7.571 & 0.002 \\
\hline
\end{tabular}


Tuberculosis and Behavioural Risk Factors: The Case with North-Western Nigeria

\begin{tabular}{|c|c|c|c|c|c|c|}
\hline \multirow[b]{2}{*}{ Model } & & \multicolumn{2}{|c|}{ Unstandardized Coefficients } & \multirow{2}{*}{$\begin{array}{c}\text { Standardized } \\
\text { Coefficients }\end{array}$} & \multirow[b]{2}{*}{$\mathrm{t}$} & \multirow[b]{2}{*}{ Sig. } \\
\hline & & $\mathrm{B}$ & Std. Error & & & \\
\hline \multirow[t]{11}{*}{1} & (Constant) & -0.769 & 1.713 & & -0.449 & 0.677 \\
\hline & Dust & 3.679 & 0.365 & 0.110 & 10.079 & 0.001 \\
\hline & God & 3.600 & 0.375 & 0.229 & 9.588 & 0.001 \\
\hline & Spiritual & 4.301 & 1.490 & 0.026 & 2.887 & 0.045 \\
\hline & Heredity & 3.598 & 0.159 & 0.265 & 22.638 & 0.000 \\
\hline & Coldwater & 3.966 & 2.859 & 0.019 & 1.387 & 0.238 \\
\hline & Diet & 3.722 & 0.652 & 0.147 & 5.712 & 0.005 \\
\hline & Infection & 4.273 & 2.435 & 0.074 & 1.755 & 0.154 \\
\hline & Unpastmilk & 3.322 & 0.807 & 0.046 & 4.118 & 0.015 \\
\hline & Smoking & 3.383 & 0.534 & 0.169 & 6.334 & 0.003 \\
\hline & Don know & 3.522 & 0.465 & 0.177 & 7.571 & 0.002 \\
\hline
\end{tabular}

To test the significance of these variables on the prevalence, the Analysis of Variance (Table 6) carried showed no statistically significant difference in the means of the variables considered, $F(19,130)=0.525, p=$ 0.947 . The finding may not be a surprise since data were based on perceptions. These could vary with the individuals, their levels of literacy and the society they come from, and, therefore, the data could be subjective. The misconception goes to show why people pay less attention to other factors such as nutrition (and consumption of unpasteurized milk), and the possibility of infection due to contacts. Of course, we have to bear in mind that this is a perception study where the views obtained could be subjective where people who take unpasteurized milk or its products will not believe that these have any relationship to TB infection.

Table 6: Results of analysis of variance on perceived causes of TB

\begin{tabular}{lccccc}
\hline & Sum of Squares & df & Mean Square & F & Sig. \\
\hline Between Groups & 569.810 & 19 & 29.990 & 0.525 & 0.947 \\
Within Groups & 7425.023 & 130 & 57.116 & & \\
Total & 7994.833 & 149 & & & \\
\hline
\end{tabular}

\section{SUMMARY, CONCLUSION AND POLICY RECOMMENDATIONS}

Among the behavioral risk factors, the regression model showed that 'ever visited a health centre to treat TB' has the highest contribution in the prevalence of tuberculosis, followed by 'ever been a cigarette smoker' and then having 'sleeping in the midst of animals'. Consumption of unpasteurized milk does not contribute to TB prevalence. There was no statistical significance in the relationships between the variables considered and TB prevalence. Therefore, even though behavioural risk factors play a role in the prevalence of pulmonary tuberculosis in the North-western region of Nigeria, this cannot be statistically proved. There could thus be some sort of synergy among the factors as their respective roles were not well pronounced in some stations.

In view of the findings, it is recommended that more detailed studies on the social life of the people within the region be carried out, with a view to understanding the behavioural risk factors for the disease. The perception that consumption of unpasteurized milk could be a causative factor of tuberculosis is rather speculative and needs to be substantiated by concrete empirical evidence. More detailed empirical research needs to be carried out to ascertain this claim, as well as research on the people who actually consume unpasteurized milk and its products. This is more so bearing the fact that individuals and societies differ in their cultures, lifestyles and behaviours.

\section{ACKNOWLEDGEMENTS}

This work was part of a PhD thesis on "The Prevalence of Pulmonary Tuberculosis in the Northwestern region of Nigeria" submitted to the Department of Geography, University of Ibadan Nigeria, 2015. It 
was sponsored by the Usmanu Danfodiyo University, Sokoto, as a study leave grant. I therefore wish to express my gratitude to the University for the sponsorship and my Supervisor, Professor S. I. Okafor, as well as the DOTS officers for releasing the necessary case registry data. My gratitude also goes to Dr N. B. Eniolorunda of the Department of Geography, Usmanu Danfodiyo University Sokoto, for assisting with data analysis and drawing some of the maps.

\section{Ethical Approval}

Approval to collect tuberculosis case registry data and permission to interview TB patients for the study were given by the management of the Directly Observed Therapy Short-Course (DOTS) centres.

\section{Conflict of Interest}

There was no actual or potential conflict of interest with the University that sponsored the Thesis and where the Thesis was carried out

\section{REFERENCES}

[1] Abubakar, U. B., Ameh, J. I., Abdulkadir, I. A., Salisu, I., Okaiyeto, S. O. and Kudu, A. C. 2011, Bovine Tuberculosis in Nigeria: A review, Veterinary research. 14 (1): 24-27.

[2] Alhaji, I. and Schnurrenberger, P. 1977. Public health significance of bovine tuberculosis in four Northern States of Nigeria. A mycobacteriological study. Nigerian Medical Journal. 7(4):384- 386.

[3] Araoye, M. O. 2004. Research Methodology with Statistics for Health and Social Sciences. Ilorin: Nathadex Publishers. Arcavia, L. and Benowitz, N. L. 2004. Cigarette smoking and infection, Achieve of International Medicine. 164:2206-2216.

[4] Arcavia, L. and Benowitz, N. L. 2004. Cigarette smoking and infection, Achieves of International Medicine. 164:2206-2216.

[5] Ariyothai, N., Podhipak, A., Akarasewi, P., Tornee, S., Smithtikarn, S. and Thongprathum, P. 2004. Cigarette smoking and its relation to pulmonary tuberculosis in adults. Southeast Asian Journal of Tropical Medicine and Public Health. 35(1):n219-227.

[6] Ayele, W. Y., Neill, S. D., Zinsstag, J., Weiss, M. G. and Pavlik, I. 2004. Bovine tuberculosis: an old disease but a new threat to Africa. International Journal of Tuberculosis and Lung Diseases. 8(8): 924937.

[7] Beals, F.T. 2007. The Risk of Bovine Tuberculosis from Raw Milk Consumption with a focus on Michigan in Wise Traditions in Food, Farming and the Healing Arts. The quarterly magazine of the Weston A. Price Foundation. Retrieved $7^{\text {th }}$ February 2012 from http://www.westonaprice.org/farm-aranch/risk-of-bovine-tb-from-raw-milk-consumption.

[8] Chigbu, L. N. and Iroegbu, C. U., 2010, Incidence and spread of Mycobacterium tuberculosis- associated infection among Aba Federal Prison inmates in Nigeria. Journal of Health, Population and Nutrition. 28(4): 327-332.

[9] Daborn, C.J., Grange, J.M., Kazwala, R.R. 1996.The bovine tuberculosis cycle - an African perspective. Social and Applied Bacteriological Symposium, 25, 27-32.

[10] Ekrakene, T and Igeleke, C. L. 2010. Prevalence of pulmonary tuberculosis among active and passive Smokers of cigarette in Benin City, Nigeria. International Journal of Biomedical and Health Sciences. 6 (1): Also available at http://www.asopah.org.

[11] Erah, P. O. and Ojieabu, W. A. 2009. Success of the control of tuberculosis in Nigeria: a review International Journal of Health Research. 2(1): 3-14 (e214p21-32) Available at http://www.ijhr.org, retrieved July 2010.

[12] Fada. A. G. 2015, Nomadic Pastoralism and the Prevalence of Pulmonary Tuberculosis (TB) in the North-Western Region of Nigeria. A PhD Thesis in the Department of Geography, Faculty of Social Sciences, University of Ibadan, Nigeria

[13] Gesler, W. M. and Kearns, R. A. 2002. Culture, place and health. London. Routledge.

[14] Itah, A. Y. and Udofia, S. M. 2005. Epidemiology and endemicity of pulmonary tuberculosis (PTB) in South-eastern Nigeria. Southeast Asia Journal of Tropical Medicine and Public Health. 36:317-323.

[15] Karim, F., Johansson, E., Diwan, V. K. and Kulane, A.2011. Community perceptions of tuberculosis: A qualitative exploration from a gender perspective. Public Health. 125: 84-89.

[16] Lam, W.K., White, N.W. and Chan-Yeung, M. M. 2004. Lung cancer epidemiology and risk factors in Asia and Africa. International Journal of Tuberculosis and Lung Diseases. : 1045-57.

[17] Lienhardt, C. Fielding, K., Sillah, J., Tunkara, A., Donkor, S., Manneh, K., Warndorff, D., Keith P. M. and Bennett, S. 2003. Risk Factors for Tuberculosis Infection in Sub-Saharan Africa: A contact study in The Gambia. American Journal of Respiratory and Critical Care Medicine. 168: 448-455. 
[18] _ _ Bah, B., Gustafson, P., Warndorff, D., Palayew, M., Lisse, I., Donkor S., Diallo, S. 2005, Investigation of the risk factors for tuberculosis: a case-control study in three countries in West Africa. International Journal of Epidemiology. 34(4): 914-923.

[19] Lien, L.T., Hang, N.T.L., Kobayashi, N., Yanai, H., Toyota, E., Sakurada, S., Thuong, P. H., Cuong, V. C., Nanri, A., Mizoue, T., Matsushita, I., Harada, N., Higuchi, K., Le Anh Tuan, L. N. and Keicho, N. 2009. Prevalence and risk factors for tuberculosis infection among hospital workers in Hanoi, Vietnam. PLoS ONE. 4(8): e6798. doi:10.1371/journal.pone.0006798

[20] Lopez De Fede, A., Stewart, J. E., Harris, M. J. and Mayfield-Smith, K.2008.Tuberculosis in socioeconomically deprived neighbourhoods: missed opportunities for prevention. International Journal of Tuberculosis and Lung Diseases. 12(12):1425-1430.

[21] Mackenbach, J. P., Stirbu, I., Roskam, A. J., Schaap, M. M., Menvielle, G., Leinsalu, M. And Kunst, A. E. 2008. Socioeconomic inequalities in health in 22 European countries. English Journal of Medicine. 358(23):2468-2481.

[22] Meade, M. S. and Earickson, R.S. 2000. Medical Geography. Second Edition. The Guilford Press, New York.

[23] Muniyandi, M. and Ramachandran, R. 2008. Socioeconomic inequalities of tuberculosis in India. Expert Opin Pharmacother. 9(10):1623-1628.

[24] Obuku, E. A., Meynell, C. Kiboss-Kyeyune, J., Blankley, S., Atuhairwe, C., Nabankema, E., Lab, M., Jeffrey, N. and Ndungutse, D. 2012. Socio-demographic determinants and prevalence of tuberculosis knowledge in three slum populations of Uganda. BMC Public Health. 12:536 doi: 10.1186/1471-2458$12-536$.

[25] Ofukwu, R.A., Oboegbulem, S.I. and Akwuobu, C. A. 2008. Zoonotic Mycobacterium species in fresh cow milk and fresh skimmed, unpasteurised market milk (nono) in Makurdi, Nigeria: implications for public health. Journal of Animal and Plant Science. 1(1): 21-25. Retrieved $2^{\text {nd }}$ July 2010 from http:// www.biosciences.elewa.org/JAPS.

[26] Oluwadare, C. O. and Bosede, I. 2010. Health seeking behaviour of tuberculosis patients in Ekiti State, Nigeria. Ethno Medicine. 4(3): 191-197.

[27] Peter, M. F., Otto, F. S., Shiirev-adiya and Chinbat, B. 1997. Health status and risk factors of Seminomadic pastoralists in Mongolia: a geographical approach. Social Science and Medicine. 44 (11): 16231647.

[28] Shitaye, J.E., Tsegaye, W. and Pavlik, I. 2007. Bovine tuberculosis infection in animal and human populations in Ethiopia: A review. Veterinary Medicine, 52(8): 317-332.

[29] Singh, M., Mynak, M. L., Kumar, L., Mathew, J. L. and Jindal, S. K. 2005. Prevalence and risk factors for transmission of infection among children in household contact with adults having pulmonary tuberculosis, Achieves of Disease in Childhood.90:624-628 doi:10.1136/adc.2003.044255.

[30] Thoen, C., LoBue, P. and De Kantor, I. 2006. The Importance Mycobacterium bovis as a zoonosis. Veterinary Microbiology. 112(2-4): 339- 345.

[31] Udo, R. K. 1970. Geographical regions of Nigeria. Heinemann Education Books Ltd. London.

[32] United States Embassy in Nigeria. January 2012 Economic Section. Retrieved $15^{\text {th }}$ September, 2012 from http://nigeria.usembassey.gov.

[33] World Health Organization. 2006. Global tuberculosis control-WHO Report. Retrieved $23^{\text {rd }}$ February 2017 from http://www.ij.healthgeographics.com/sfx_links.asp?ul-1476-072X-5-33\&biblB7.WHO/HTM/TB/2006.331.

[34] Yumi, U. and Tooru, M. 2007. Tuberculosis as a zoonosis from a veterinary perspective. Compendium of Immunological and Infectious Diseases. 30: 415-425. 